\title{
FAKTOR YANG BERHUBUNGAN DENGAN KEJADIAN STRES KERJA PADA PERAWAT ICU DI RSUD Dr. R.M. DJOELHAM BINJAI TAHUN 2020
}

\author{
Associated Factors Events Job Stress In Nurses At Icu \\ Room In Dr. R.M. Djoelham Hospital Binjai In 2020 \\ Yose Dodi Pratama', Arifah Devi Fitriani' ${ }^{2}$ Juliandi Harahap ${ }^{3}$ \\ ${ }^{1}$ Mahasiswa Pascasarjana IKM Fakultas Kesehatan Masyarakat, Institut Kesehatan \\ Helvetia, Medan, Indonesia \\ ${ }^{2}$ Dosen IKM Fakultas Kesehatan Masyarakat, Institut Kesehatan Helvetia, Medan, \\ Indonesia \\ ${ }^{3}$ Dosen IKM Fakultas Kesehatan Masyarakat, Institut Kesehatan Helvetia, Medan, \\ Indonesia \\ *Penulis Korenpodensi : yosedodip@gmail.com ${ }^{1}$, arifahdevifitriani@helvetia.ac.id ${ }^{2}$, \\ juliandiharahap@yahoo.com ${ }^{3}$
}

\begin{abstract}
Abstrak
Stres kerja dapat disebabkan karena tuntutan pekerjaan yang diberikan tidak sesuai dengan kemampuan pekerja dan kurang terjaminnya kesejahteraan pekerja. Berdasarkan survei pendahuluan dengan menggunakan kuesioner yang dilakukan pada 8 orang perawat ICU didapatkan informasi bahwa perawat yang bekerja di ruang ICU RSUD Dr. R.M. Djoelham Kota Binjai sering mengeluh adanya kelelahan dan kewalahan saat menghadapi pasien dengan keadaan kritis. Tujuan penelitian ini yaitu untuk mengetahui faktor yang berhubungan dengan kejadian stres kerja pada perawat ICU di RSUD Dr. R.M. Djoelham Binjai Tahun 2020.

Jenis penelitian yang digunakan dalam penelitian ini adalah penelitian kuantitatif dan kualitatif (mixed method), pengambilan data secara kuantitatif dengan menggunakan kuesioner, kemudian pengambilan data kualitatif melalui wawancara untuk melihat temuan dilapangan yang dilakukan secara terpisah.

Hasil penelitian kuantitatif menunjukkan beban kerja $=0,009$, tanggung jawab, $=0,030$, keamanan kerja $=0,032$, menunjukkan adanya hubungan terhadap kejadian stres kerja pada perawat ICU. Sedangkan umur $p=0,670$, jenis kelamin $=0,396$, masa kerja $=0,695$, status pernikahan $=0,331$, hubungan interpersonal $=1,000$, menunjukkan tidak ada hubungan terhadap kejadian stres kerja pada perawat ICU.

Kesimpulan dalam penelitian ini adanya hubungan beban kerja, tanggung jawab, keamanan kerja terhadap stres kerja pada perawat ICU, sedangkan umur, jenis kelamin, masa kerja, status pernikahan tidak ada hubungan terhadap stres kerja pada perawat ICU. Dengan hasil penelitian ini diharapkan pihak rumah sakit memberikan kebijakan yang dapat meningkatkan kinerja perawat.
\end{abstract}

$\begin{array}{ll}\text { Kata kunci } & : \text { Stres Kerja, Perawat ICU } \\ \text { Daftar Pustaka } & : 22 \text { Buku + 68 Jurnal }\end{array}$


Journal of Healthcare Technology and Medicine Vol. 6 No. 2 Oktober 2020

Universitas Ubudiyah Indonesia

e-ISSN : 2615-109X

\begin{abstract}
Job stress could be caused by demands of jobs given are not in accordance with the worker's ability and welfare is not guaranteed. Based on a preliminary survey, it was found the nurses who worked at the ICU room of Dr. R.M. Djoelham Hospital in Binjai often complains of being tired and overwhelmed when dealing with patients with critical conditions. The purpose of this study was to determine the factors associated with the incidence of work stress on ICU nurses at Dr. R.M. Djoelham Binjai in 2020.

The type of research used in this research was quantitative and qualitative research (mixed method). Quantitative data were taken by using a questionnaire, then collecting qualitative data through interviews to find out the fields which were carried out separately.

The results of quantitative research showed workload $(p=.009)$, responsibility $(p=.030)$, job security $(p=.032)$, indicating a relationship to the incidence of Job stress on nurses. While age $(p=.670)$, gender $(p=.396)$, tenure $(p=.695)$, marital status $(p=.331)$, interpersonal relationship $(p=1.000)$, indicating there is no relationship to the incidence of job stress on nurses.

The conclusion showed that a relationship between workload, responsibility, job security and job stress on nurses at ICU rooms was found, but for age, gender, tenure, marital status had no relationship with job stress on nurses. With the results of this study, it is hoped that the hospital will provide policies that can improve the performance of nurses.
\end{abstract}

$\begin{array}{ll}\text { Keywords } & : \text { Job Stress, ICU Nurse } \\ \text { Bibliography } & : 22 \text { Books }+68 \text { Journals }\end{array}$


Journal of Healthcare Technology and Medicine Vol. 6 No. 2 Oktober 2020

Universitas Ubudiyah Indonesia

e-ISSN : 2615-109X

\section{PENDAHULUAN}

Tenaga kesehatan memiliki peran penting dalam penyelenggaraan pelayanan kesehatan. Tenaga kesehatan merupakan setiap orang yang mengabdikan diri di bidang kesehatan yang memiliki pengetahuan dan keterampilan di bidang kesehatan yang untuk jenis tertentu memerlukan kewenangan dalam melakukan upaya kesehatan. Tenaga kesehatan diklasifikasikan ke dalam beberapa kelompok antara lain tenaga medis, tenaga psikologi klinis, tenaga keperawatan, tenaga kebidanan, tenaga kefarmasian, tenaga kesehatan masyarakat, tenaga kesehatan lingkungan, tenaga gizi, tenaga keterapian fisik, tenaga teknik biomedika, tenaga kesehatan tradisional dan tenaga kesehatan lainnya (1).

Intensive care unit (ICU) adalah suatu bagian dari rumah sakit yang mandiri, dengan staf yang khusus dan perlengkapan yang khusus yang ditujukan untuk observasi, perawatan dan terapi pasien-pasien yang menderita penyakit akut, cedera atau penyulit-penyulit yang mengancam nyawa atau potensial mengancam nyawa. ICU menyediakan kemampuan dan sarana prasarana serta peralatan khusus untuk menunjang fungsi-fungsi vital dengan menggunakan keterampilan staf medik, perawat dan staf lain yang berpengalaman dalam pengelolaan keadaan-keadaan tersebut (6).

Perawat ICU berbeda dengan perawat lain. Tingkat pekerjaan dan pengetahuan perawat ICU lebih kompleks dibandingkan dengan perawat bagian lain di rumah sakit, karena bertanggung jawab mempertahankan homeostasis pasien untuk berjuang melewati kondisi kritis/terminal yang mendekati kematian (7). Perawat ICU mempunyai peran yang berbeda dengan perawat yang bekerja di unit lain. Perawat ICU sebagai salah satu tim kesehatan harus memiliki pengetahuan dan keahlian khusus, meliputi kemampuan menangani kondisi pasien yang kritis, bekerja dengan cepat, tepat, teliti, dan senantiasa cermat dalam mengobservasi dan menilai keadaan umum pasien yang cendrung fluktuatif. Perawat ICU juga harus mempunyai tingkat pengetahuan dan keterampilan yang kompleks karena bertanggung jawab untuk mempertahankan homeostasis pasien untuk melewati kondisi kritis. Kondisi pasien yang kritis, beban kerja yang sangat tinggi, lingkungan ICU dengan peralatan yang canggih, dapat menjadi sumber stres bagi perawat yang bertugas di ICU (8).

Penelitian yang dilakukan The National Institute Occupational Safety and Health (NIOSH) menunjukkan bahwa pekerjaan-pekerjaan yang berhubungan dengan rumah sakit atau kesehatan memiliki kecenderungan tinggi untuk terkena stres kerja atau depresi, tenaga kesehatan yang memiliki resiko tinggi untuk mengalami stres kerja tersebut adalah tenaga 
Journal of Healthcare Technology and Medicine Vol. 6 No. 2 Oktober 2020

Universitas Ubudiyah Indonesia

e-ISSN : 2615-109X

keperawatan (9). Sedangkan Rahman (2010) American National Association for Occupational Health $(A N A O H)$ menempatkan kejadian stres kerja pada perawat berada diurutan paling atas pada empat puluh pertama kasus stres kerja pada pekerja (10).

Stres kerja merupakan segala bentuk rangsangan atau respon dari tubuh manusia baik yang berasal dari luar maupun dari dalam tubuh manusia itu sendiri yang dapat menimbulkan dampak yang merugikan seperti menurunnya kesehatan atau menderita suatu penyakit. Stres kerja juga dapat diartikan sebagai ketidakmampuan pekerja dalam melaksanakan tuntutan pekerjaan karena suatu ketidaknyamanan dalam bekerja. Stres kerja muncul akibat adanya stressor yang diterima oleh tubuh yang kemudian tubuh akan memberikan respon dalam bentuk respon emosional atau fisiologis yang beragam (11).

Ketidakberdayaan dan perasaan tertekan pada perawat dalam menghadapi stresor pekerjaan akan memberikan berbagai dampak negatif. Stres yang berlebihan dapat menyebabkan kelelahan fisik dan emosional. Selain itu, stres juga akan mempengaruhi produktivitas kerja sehingga akan mempengaruhi mutu pelayanan kesehatan yang diberikan kepada pasien (12).

Stres kerja dapat disebabkan karena tuntutan pekerjaan yang diberikan tidak sesuai dengan kemampuan pekerja dan kurang terjaminnya kesejahteraan pekerja. Faktor yang menyebabkan stres kerja sangat tergantung dengan sifat dan kepribadian seorang pekerja. Suatu keadaan yang dapat menimbulkan hal yang sama terhadap pekerja yang lain. Perbedaan respon antara individu disebabkan karena faktor sosial dan psikologis yang dapat merubah dampak stressor yang diterima oleh tubuh (13).

Hasil penelitian Health and Safety Executive pada tahun 2015 menunjukkan bahwa tenaga profesional kesehatan, guru dan perawat memiliki tingkat stres tertinggi dengan angka prevalensi sebesar 2500, 2190 dan 3000 kasus per 100.000 orang pekerja pada periode 2011/2012, 2013/2014, dan 2014/2015 (15).

RSUD Dr. R.M. Djoelham Binjai merupakan salah satu perangkat daerah Pemerintah Kota Binjai yang dibentuk berdasarkan Peraturan Daerah Kota Binjai Nomor 16 Tahun 2011 tentang organisasi dan Tata Kerja Lembaga Teknis Daerah Kota Binjai. Kedudukan RSUD Dr. R.M. Djoelham Binjai diatur dengan Peraturan Walikota Binjai Nomor 27 Tahun 2012 tentang rincian Tugas Pokok dan fungsi rumah sakit umum daerah Dr. R.M. Djoelham binjai yang menyebutkan rumah sakit umum daerah merupakan unsur pendukung tugas Walikota yang 
Journal of Healthcare Technology and Medicine Vol. 6 No. 2 Oktober 2020

Universitas Ubudiyah Indonesia

e-ISSN : 2615-109X

dipimpin oleh seorang Direktur yang berada di bawah dan bertanggung jawab kepada Walikota melalui sekretaris daerah.

Direktur Rumah Sakit Umum Daerah mempunyai tugas membantu walikota dalam melaksanakan penyusunan dan pelaksanaan kebijakan daerah di bidang kesehatan kepada masyarakat dengan mengutamakan upaya pencegahan, pengobatan, pemulihan yang dilaksanakan secara serasi terpadu dengan upaya peningkatan dan melaksanakan upaya rujukan.

RSUD Dr. R.M. Djoelham Binjai pada ruangan ICU memiliki 21 perawat dengan jenis kelamin 9 orang laki-laki dan 12 orang perempuan. Di ruangan ICU diberlakukan sistem shift dengan 4 shift yaitu pagi, sore, malam dan hari libur dengan penempatan 3-4 perawat dalam satu shift. Pergantian shift dilakukan 3 hari sekali, ruangan perawat dengan ruangan pasien ICU berada dalam satu ruangan.

Berdasarkan survei pendahuluan dengan menggunakan kuesioner yang dilakukan pada 8 orang perawat ICU didapatkan informasi bahwa perawat yang bekerja di ruang ICU RSUD Dr. R.M. Djoelham Kota Binjai sering mengeluh adanya kelelahan dan kewalahan saat menghadapi pasien dengan keadaan kritis dan juga disebabkan karena kondisi beban kerja, tanggung jawab, serta keamanan kerja yang berat dapat menjadi salah satu kemungkinan potensi pemicu terjadinya keluhan yang dirasakan perawat.

Berdasarkan uraian diatas dapat disimpulkan bahwa adanya faktor-faktor yang berhubungan dengan terjadinya stres kerja pada perawat ICU di RSUD Dr. R.M. Djoelham Binjai.

\section{BAHAN DAN METODE}

Jenis penelitian yang digunakan dalam penelitian ini adalah penelitian kuantitatif dan kualitatif (mixed method) (74), pengambilan data secara kuantitatif dengan menggunakan kuesioner, responden diminta untuk mengisi kuesioner yang diberikan, kemudian pengambilan data kualitatif melalui wawancara. Populasi penelitian adalah seluruh perawat yang bekerja dibagian ICU RSUD Dr. R.M. Djoelham Binjai yang berjumlah sebanyak 21 orang.

\section{HASIL PENELITIAN DAN PEMBAHASAN}

\section{Analisis Hubungan Antara Umur dengan Stres Kerja}

Hasil penelitian ini sejalan dengan penelitian yang dilakukan oleh Felix Pramudaya W (2008) bahwa tidak ada hubungan umur dengan stres kerja pada perawat dengan P-value 0,624 
Journal of Healthcare Technology and Medicine Vol. 6 No. 2 Oktober 2020

Universitas Ubudiyah Indonesia

e-ISSN : 2615-109X

(78). Hasil ini juga sejalan dengan penelitian yang dilakukan oleh Nurazizah (2017) menunjukkan bahwa tidak ada hubungan antara umur dengan stres kerja dengan nilai P-value 0,547 (79).

Hal tersebut juga sejalan dengan penelitian Sugeng (2015) menurutnya semakin tua umur seseorang, maka akan semakin meningkat kedewasaanya, kematangan jiwanya dan lebih mampu dalam melaksanakan tugas dan tanggung jawabnya. Seiring dengan bertambahnya umur maka akan meningkat pula kemampuan membuat keputusan, berpikir rasional, semakin bijaksana, mampu mengendalikan emosi, dan terbuka dengan pandangan atau pendapat orang lain sehingga ketahanan dirinya terhadap stres meningkat (66).

\section{Analisis Hubungan Antara Jenis Kelamin Dengan Stres Kerja}

Hasil ini sejalan dengan penelitian yang dilakukan oleh Felix Pramudaya W (2008) bahwa tidak ada hubungan antara jenis kelamin dengan stres kerja pada perawat dengan nilai p-value 0.380 yang artinya tidak ada pengaruh yang secara signifikan terhadap kondisi stres (78).

Stres kerja yang dialami oleh perawat laki-laki dan wanita bisa saja berbeda hal tersebut dikarenakan secara fisik dan mental berbeda, serta respon terhadap stresor yang berbeda pula. Sesuai dengan pendapat Munandar (2001), stres ditentukan oleh individunya sendiri. Reaksireaksi psikologis, fisiologis dan atau dalam bentuk perilaku terhadap stres adalah hasil interaksi situasi dengan individunya (60).

Hal ini tidak sesuai dengan pendapat Anitawidanti (2010), tuntutan peran ganda umumnya dialami perempuan yang melibatkan diri dalam lingkungan organisasi, yaitu sebagai wanita karir dan ibu rumah tangga sehingga lebih rentan mengalami stres. Tuntutan pekerjaan, rumah tangga dan ekonomi berpotensi wanita karir rentan mengalami stres (80).

Pada ruang ICU RSUD Dr. R.M. Djoelham Binjai tidak membedakan pekerjaanpekerjaan yang harus dikerjakan antara laki-laki dan perempuan sehingga kesempatan terkena stres kerja antara laki-laki dan perempuan adalah sama dan bila ditinjau dari jumlah perawat yang menjadi responden penelitian ini diketahui bahwa jumlah responden perawat perempuan lebih banyak dibandingkan dengan responden perawat laki-laki. Sehingga proporsi responden perawat laki-laki dan perempuan tidak proporsional dan belum dapat menggambarkan perbedaan stres yang sesungguhnya.

Sedangkan menurut Sugeng (2015) tidak adanya hubungan antara jenis kelamin dengan stres kerja disebabkan oleh tidak adanya perbedaan yang konsisten pada laki-laki dan 
Journal of Healthcare Technology and Medicine Vol. 6 No. 2 Oktober 2020

Universitas Ubudiyah Indonesia

e-ISSN : 2615-109X

perempuan dalam hal kemampuan berfikir, menyelesaikan masalah, menyesuaikan diri dengan lingkungan kerja, motivasi, keterampilan, dan analisis (66).

\section{Analisis Hubungan Antara Masa Kerja Dengan Stres Kerja}

Masa kerja baru maupun lama dapat menjadi pemicu terjadinya stres kerja. Stres yang timbul akibat masa kerja lama dapat disebabkan oleh kebosanan yang timbul akibat rutinitas kerja yang monoton (81). Selain itu masa kerja baru juga dapat menjadi pemicu stres kerja karena faktor yang mempengaruhi stres kerja selain kejenuhan dalam bekerja adalah pengalaman seseorang dalam menghadapi suatu pekerjaan (82).

\section{Analisis Hubungan Antara Status Pernikahan Dengan Stres Kerja}

Hasil penelitian ini sejalan dengan penelitian yang dilakukan oleh Aiska (2014) bahwa tidak ada hubungan antara status pernikahan dengan stres kerja pada perawat (83). Tidak adanya hubungan antara status pernikahan dengan stres kerja dapat disebabkan karena status pernikahan dapat mempengaruhi perilaku seseorang baik secara positif maupun negatif tergantung bagaimana seseorang menilai suatu masalah. Seperti yang diungkapkan Siagian (2009) bahwa status pernikahan berpengaruh terhadap perilaku seseorang baik secara positif maupun negatif. Pasangan dengan pernikahan yang berjalan dengan baik dapat saling memberikan dukungan emosional yang positif sehingga mampu meringankan tekanan yang ada di lingkungan kerja (84).

Menurut Muthmainah S (2012), kondisi menikah dapat berpengaruh pada emosi seseorang, dimana terjadi perubahan hubungan yang bergeser kearah kematangan hubungan yang memberikan kenyamanan dan saling ketergantungan. Sehingga individu yang sudah menikah memiliki teman untuk berbagi dalam menyelesaikan suatu masalah (74).

\section{Analisis Hubungan Antara Beban Kerja Dengan Stres Kerja}

Hasil penelitian ini sejalan dengan penelitian yang dilakukan oleh Astuti (2012) bahwa terdapat hubungan beban kerja dengan stres kerja perawat pelaksana di Intensive Care Unit (ICU) RSUD Polewali Mandar, analisa data diukur dengan menggunakan uji Fisher Exact Test $(0,01<0,05)(85)$.

Menurut Utomo (2008), beban kerja adalah sekumpulan atau sejumlah kegiatan yang harus diselesaikan oleh suatu unit organisasi atau pemegang jabatan dalam jangka waktu tertentu. Pengukuran beban kerja diartikan sebagai suatu teknik untuk mendapatkan informasi tentang efisiensi dan efektivitas kerja suatu unit organisasi, atau pemegang jabatan yang dilakukan secara sistematis dengan menggunakan teknik analisis jabatan, teknik analisis beban 
Journal of Healthcare Technology and Medicine Vol. 6 No. 2 Oktober 2020

Universitas Ubudiyah Indonesia

e-ISSN : 2615-109X

kerja atau teknik manajemen lainnya. Lebih lanjut dikemukakan pula, bahwa pengukuran beban kerja merupakan salah satu teknik manajemen untuk mendapatkan informasi jabatan, melalui proses penelitian dan pengkajian yang dilakukan secara analisis. Informasi jabatan tersebut dimaksudkan agar dapat digunakan sebagai alas untuk menyempurnakan aparatur baik di bidang kelembagaan, ketatalaksanaan, dan sumber daya manusia (86).

\section{Analisis Hubungan Interpersonal Dengan Stres Kerja}

Penyebab stres di tempat kerja yaitu hubungan dalam organisasi. Stres ini muncul jika seseorang pekerja memiliki hubungan yang tidak baik, apakah itu dengan pimpinannya, teman sejawatnya ataupun para bawahannya. Hal ini juga berkaitan dengan kesulitan di dalam mendelegasian tanggung jawabnya kepada para bawahannya. Selain itu juga yang menjadi penyebab stres lainnya adalah konflik dalam peranan, perkembangan karir dalam organisasi, keadaan pekerja dalam organisasi, perubahan yang sering dalam organisasi, suasana di tempat kerja, kesetiaan yang terbagi antara kehendak organisasi dan kehendak sendiri (88).

Berdasarkan hasil penelitian dapat dilihat bahwa hampir seluruh responden memliki hubungan yang baik bagi sesama teman kerja maupun atasan. Hal ini dapat dilihat dari pernyataan mereka yang tidak berselisih paham baik antara sesama teman kerja maupun atasan karena mereka selalu mampu menyelesaikan konflik dengan orang-orang sekitarnya. Saling peduli, menjalin komunikasi yang baik, saling menghargai hasil pekerjaan teman kerja serta meluangkan waktu untuk bergaul dengan teman kerja dan atasan dilakukan sehingga terciptalah hubungan interpersonal yang baik.

\section{Analisis Hubungan Antara Tanggung Jawab Dengan Stres Kerja}

Hasil ini sejalan dengan penelitian yang dilakukan oleh Supriatna (2014) yang menyatakan bahwa tanggung jawab terhadap orang lain merupakan salah satu faktor yang menyebabkan stres kerja pada perawat di RS Muhammadiyah Bandung (89).

Bentuk tanggung jawab perawat diantaranya adalah tanggung jawab terhadap keamanan yaitu menjaga pasien agar selalu dalam kondisi tenang, tanggung jawab terhadap kebutuhan pasien yaitu memberikan perawatan sebaik mungkin sesuai dengan kebutuhan pasien selama masa penyembuhan, tanggung jawab moral untuk merawat pasien dengan penuh kasih sayang dan sikap peduli serta banyaknya tanggung jawab pekerjaan yang harus dilakukan sesuai dengan harapan orang lain agar orang lain merasa puas dengan pekerjaan yang telah dilakukan (89). 
Journal of Healthcare Technology and Medicine Vol. 6 No. 2 Oktober 2020

Universitas Ubudiyah Indonesia

e-ISSN : 2615-109X

\section{Analisis Hubungan Antara Keamanan Kerja Dengan Stres Kerja}

Hasil ini sejalan dengan penelitian yang dilakukan oleh Cece Suriani Ismail (2013) yang menyatakan bahwa ada hubungan antara keamanan kerja dengan stres kerja pada perawat di RSU Bahteramas Provinsi Sultra $(\mathrm{p}<0,05)$. Berdasarkan hasil uji derajat kekuatan hubungan, kedua variable tersebut memiliki derajat kekuatan hubungan yang sedang $(\mathrm{C}=0,478)(33)$. Faktor keamanan kerja, khususnya yang berkaitan dengan risiko terinfeksi menjadi salah satu faktor penyebab stres kerja. Hasil ini sejalan dengan studi yang dilakukan oleh Circenis dan Inga (2012) terhadap 241 perawat di latvia, 41,9\% menandai risiko terinfeksi sebagai salah satu faktor yang paling berperan terhadap stres kerja (90).

Beberapa penyebab utama lingkungan kerja menjadi kurang aman terutama bersumber dari pekerjaan yang mempunyai potensi kecelakaan yang tinggi, pekerja yang berhubungan langsung dengan pasien dan pekerjaan yang terlalu memerlukan sikap hati-hati. Pada bagian ICU misalnya, perawat harus selalu memantau kesadaran pasien dari waktu ke waktu, mengawasi fungsi alat-alat vital tubuh pasien, dan harus selalu berhati-hati karena pekerjaan tersebut berhubungan langsung dengan kehidupan pasien. Pelayanan seperti itu membutuhkan kedisiplinan dan ketelitian serta pengawasan dan perawatan khusus dari perawat sehingga mudah mengalami stres.

Hardjana (1994) mengatakan bahwa rasa aman juga berhubungan dengan keamanan fisik, misalnya bila dalam bekerja atau oleh pekerjaan yang ditanganinya, mudah terkena celaka dan keselamatannya terus menerus dipertaruhkan. Salah satu keamanan kerja adalah jaminan pensiun sesudah selepas kerja. Namun dengan tersedia uang pensiun pun tidak sedikit orang yang mengalami stres. Kemungkinan terkena stres itu semakin tinggi bila selepas kerja tidak tersedia jaminan pensiun (73).

\section{KESIMPULAN}

Berdasarkan hasil penelitian yang telah dilakukan dapat disimpulkan sebagai berikut:

1. Tidak ada hubungan antara umur dengan kejadian stres kerja pada perawat ICU di RSUD Dr. R.M. Djoelham Binjai Tahun 2020.

2. Tidak ada hubungan antara jenis kelamin dengan kejadian stres kerja pada perawat ICU di RSUD Dr. R.M. Djoelham Binjai Tahun 2020.

3. Tidak ada hubungan antara masa kerja dengan kejadian stres kerja pada perawat ICU di RSUD Dr. R.M. Djoelham Binjai Tahun 2020.

4. Tidak ada hubungan antara status pernikahan dengan kejadian stres kerja pada perawat ICU di RSUD Dr. R.M. Djoelham Binjai Tahun 2020. 
5. Ada hubungan antara beban kerja dengan kejadian stres kerja pada perawat ICU di RSUD Dr. R.M. Djoelham Binjai Tahun 2020 sedangkan dari hasil penelitian kualitatif bahwa beban kerja sebagai perawat ICU berat.

6. Tidak ada hubungan antara hubungan interpersonal dengan kejadian stres kerja pada perawat ICU di RSUD Dr. R.M. Djoelham Binjai Tahun 2020 sedangkan dari hasil penelitian kualitatif bahwa hubungan interpersonal perawat dengan rekan kerja terjalin baik.

7. Ada hubungan antara tanggung jawab dengan kejadian stres kerja pada perawat ICU di RSUD Dr. R.M. Djoelham Binjai Tahun 2020 sedangkan dari hasil penelitian kualitatif bahwa tanggung jawab sebagai perawat ICU berat.

8. Ada hubungan antara keamanan kerja dengan kejadian stres kerja pada perawat ICU di RSUD Dr. R.M. Djoelham Binjai Tahun 2020 sedangkan dari hasil penelitian kualitatif keamanan kerja sudah cukup baik.

9. Berdasarkan hasil penelitian dapat dilihat bahwa dari 8 variabel penelitian terdapat 3 variabel yang signifikan yaitu beban kerja ( $\mathrm{p}$ value $=0,009$ ), tanggung jawab ( $\mathrm{p}$ value $=$ 0,030 ), dan keamanan kerja ( $\mathrm{p}$ value $=0,032$ ). Dari data diatas didapatkan bahwa variabel yang paling dominan berhubungan dengan stres kerja adalah beban kerja ( $\mathrm{p}$ value $=0,036$ ) dengan $(\mathrm{OR}=17,146)$.

10. Berdasarkan hasil penelitian menurut informasi dari informan bahwa beban kerja dan tanggung jawab sebagai perawat ICU berat dengan berbagai alasan salah satunya menjadi rumah sakit rujukan di kota binjai.

11. Berdasarkan hasil penelitian menurut informasi dari informan bahwa hubungan interpersonal dan keamanan kerja sudah baik karena disediakan alat pelindung diri, pengetahuan serta edukasi agar menjalakan tugasnya sesuai SOP.

12. Berdasarkan hasil penelitian menurut informasi dari informan bahwa tidak adanya penghargaan secara khusus yang diberikan kepada perawat ICU dan adanya beberapa perawat yang mendapatkan tugas tambahan diluar tugas pokok sebagai seorang perawat.

\section{SARAN}

1. Bagi peneliti selanjutnya agar dapat digunakan sebagai dasar untuk penelitian selanjutnya tentang variabel lain yang berhubungan terhadap stres kerja pada perawat.

2. Bagi institusi pendidikan diharapkan menjadi bahan pustaka dan referensi bagi mahasiswa/i mengenai faktor yang berhubungan dengan stres kerja pada perawat.

3. Bagi pihak rumah sakit sebaiknya pihak rumah sakit memberikan pendidikan ataupun pelatihan yang dapat meningkatkan kinerja perawat di ruang ICU agar dapat menghasilkan kinerja yang optimal, dan juga memberikan apresiasi terhadap perawat yang mempunyai kinerja baik dan memberikan kesempatan seluas-luasnya untuk mengembangkan potensi yang dimiliki.

\section{DAFTAR PUSTAKA}

1. Menteri Hukum dan Hak Asasi Manusia Republik Indonesia. Undang-Undang Republik Indonesia Nomor 36 Tahun 2014 Tentang Tenaga Kesehatan. Menteri Hukum dan Hak Asasi Manusia Republik Indonesia. 2014.

2. Asmadi. Konsep Dasar Keperawatan. Jakarta: Buku Kedokteran EGC; 2008.

3. Pieter HZ, Lubis NL. Pengantar Psikologi dalam Keperawatan. Pengantar Psikologi dalam Keperawatan. Jakarta: Kencana Prenada Media Group; 2010.

4. Sumijatun. Konsep Dasar Menuju Keperawatan Profesional. Jakarta: Trans Info Media; 2010.

5. Hendrawati M. Hubungan Antara Tingkat Stres Kerja Perawat Dengan Kinerja Perawat 
Journal of Healthcare Technology and Medicine Vol. 6 No. 2 Oktober 2020

Universitas Ubudiyah Indonesia

e-ISSN : 2615-109X

Di Rumah Sakit Marga Husada Wonogiri Surakarta. Sekol Tinggi Ilmu Kesehat Kusuma Husada Surakarta. 2015;

6. Muthmainah I. Faktor-faktor Penyebab Stres Kerja di Ruangan ICU Pelayanan Jantung Terpadu dr Cipto Mangunkusumo Jakarta. Cipto Mangukusuma Depok Fak Ilmu Keperawatan Progr Stud Sarj Keperawatan. 2012;

7. Hudak \& Gallo. Keperawatan Kritis: Pendekatan Holistik, Volume 1 Edisi 6. Jakarta: EGC. Jakarta: Buku Kedokteran EGC; 2010.

8. Meltzer LS, Huckabay LM. Critical Care Nurses Perceptions of Futile Care and Its Effect in Burnout. American Journal of Critical Care. Am J Crit care. 2004;13(3):2028 .

9. NIOSH CDC. Exposure to Stress: Occupational Hazards in Hospitals. Dep Heal Hum Serv centers Dis Control Prev Natl Institute DHHS Publ. 2008;

10. Rahman F. Strategi Coping Perawat Rumah Sakit Jiwa Daerah Surakarta (Fenomena pada Perawat di RSJD Surakarta). 2010;

11. Tarwaka, Bakri SHA. Ergonomi untuk Keselamatan, Kesehatan Kerja dan Produktivitas. Surakarta: Uniba Press; 2016.

12. Hamdan- Mansour AM, Al- Gamal E, Puskar K, Yacoub M, Marini A. Mental Health Nursing In Jordan: An Investigation Into Experience, Work Stress And organizational support. International Journal of Mental Health Nursing. Int J Ment Health Nurs. 2011;20(2):86-94.

13. Biru M, Utami HN, Mayowan Y. Analisis Faktor-Faktor Stres Kerja yang Mempengaruhi Kinerja Karyawan (Studi pada karyawan Tetap Pg. Kebon Agung Kabupaten Malang). J Adm Bisnis. 2016;39(2):50-6.

14. Revalicha NS. Perbedaan Stres Kerja Ditinjau dari Shift Kerja pada Perawat Di RSUP Dr. Soetomo Surabaya. J Psikol Ind dan Organ. 2013;1(2):16-21.

15. Executive HS. Work related stress, anxiety and depression statistics in Great Britain 2016. Suffolk Heal Saf Exec. 2016;

16. Wollah MO, Rompas S, Kallo V. Hubungan Antara Stres Kerja Perawat dengan Kinerja Perawat di Instalasi Gawat Darurat dan Intensive Care Unit RSU Pancaran Kasih GMIM Manado. J Keperawatan. 2017;5(2).

17. Damopoli RF, Manampiring AE, Doda D V. Hubungan Kekerasan Dengan Stres Kerja Pada Perawat Unit Gawat Darurat Dan Intensive Care Unit Rumah Sakit Di Kota Bitung Dan Kabupaten Minahasa Utara. KESMAS. 2019;8(3).

18. Difayoga R, Yuniawan A. Pengaruh Stres Kerja, Kepuasan Kerja, dan Lingkungan Kerja Terhadap Kinerja Perawat (Studi pada RS Panti Wilasa Citarum Semarang). Diponegoro J Manag. 2015;4(1):250-9.

19. Yanto A, Rejeki S. Faktor-faktor Yang Berhubungan Dengan Penurunan Stres Kerja Perawat Baru di Semarang. Nurscope. J Keperawatan dan Pemikir Ilm. 2017;3(1):1-10.

20. Sari IC, Rukayah S, Barsasella D. Hubungan Beban Kerja Dengan Stres Kerja Perawat di Rumah Sakit Bhakti Kartini Bekasi. J Persada Husada Indones. 2017;4(15):9-19.

21. Nopa I. Pengaruh Stres Kerja Terhadap Kinerja Perawat Ruang Rawat Inap RSUD Tanjung Pura Langkat Tahun 2016 [Tesis]. Univ Sumatera Utara. 2016;

22. Lumingkewas M, Warouw H, Hamel R. Hubungan Kondisi Kerja dengan Stres Kerja Perawat Dirungan Intasalasi Gawat Darurat Medik RSUP Prof. Dr. RD Kandou Manado. J keperawatan. 2015;3(3).

23. Yudi D, Tangka JW, Wowiling F. Hubungan Beban Kerja Fisik Dan Mental Perawat Dengan Penerapan Patient Safety Di IGD Dan ICU RSU GMIM Pancaran Kasih Manado 2019. J KEPERAWATAN. 2019;7(1):1-9. 
Journal of Healthcare Technology and Medicine Vol. 6 No. 2 Oktober 2020

Universitas Ubudiyah Indonesia

e-ISSN : 2615-109X

24. Hardani H. Stres Kerja Dan Kepuasan Kerja Dengan Kualitas Hidup Perawat ICU Di RS Tipe B. J Endur Kaji Ilm Probl Kesehat. 2016;1(3):113-20.

25. Suerni T. Analisis faktor-faktor yang berhubungan dengan tingkat stres perawat di ICU RSU Di Jawa Tengah [Tesis]. Fak Ilmu Keperawatan, Progr Stud Megister Keperawatan JakartA. 2012;

26. Malisa S. Gambaran Tingkat Stres Perawat Di Ruangan ICU (Intensive Care Unit) Dan ICCU (Intensive Cardiac Care Unit) RSUD Dr. Soedarso Pontianak. J ProNers. 4(1).

27. Mulyani Y, Ulfah L. Hubungan Mekanisme Koping Dengan Stres Kerja perawat IGD Dan ICU Di RSUD Ulin Banjarmasin. AL-ULUM J Ilmu Sos dan Hum. 2017;3(2).

28. Fuada N, Wahyuni I, Kurniawan B. Faktor-Faktor Yang Berhubungan Dengan Stres Kerja Pada Perawat Kamar Bedah Di Instalasi Bedah Sentral RSUD K.R.M.T Wongsonegoro Semarang. J Kesehat Masy. 2017;5(5):255-63.

29. Salmawati L. Hubungan Penerapan Sistem Manajemen Keselamatan dan Kesehatan Kerja dengan Motivasi Kerja dan Stres Kerja pada Perawat di RSU Anutapura Palu. J Manaj Pelayanan Kesehat. 2015;18(1):4-6.

30. Prihatini LD. Analisis Hubungan Beban Kerja Dengan Stres Kerja Perawat Di Tiap Ruang Rawat Inap RSUD Sidikalang [Tesis]. Univ Sumatera Utara. 2007;

31. Martyastuti NE, Isrofah I, Janah K. Hubungan Beban Kerja Dengan Tingkat Stres Perawat Ruang Intensive Care Unit dan Instalasi Gawat Darurat. J Kepemimp dan Manaj Keperawatan. 2019;2(1):9-15.

32. Hafizah R, Rachmadi F, Mallyya A. Perbedaan Stres Kerja Antara Perawat Instalasi Gawat Darurat (IGD) Dan Perawat Intensive Care Unit (ICU) Rsud Sultan Syarif Mohamad Alkadrie Kota Pontianak. J ProNers. 2016;3(1):1-13.

33. Ismail CS, Arsin HAA, Maidin HMA. Analisis Faktor Yang Berhubungan Dengan Stres Kerja Pada Perawat Di Rumah Sakit Umum Bahteramas Provinsi Sulawesi Tenggara Tahun 2013 [Tesis]. Univ Hasanudin. 2013;

34. Zukhra RM. Mekanisme Koping Perawat Dalam Menghadapi Stres Kerja Di Intensive Care Unit (ICU) RSUD Arifin Achmad Pekanbaru: Studi Fenomenologi [Tesis]. Univ Sumatera Utara. 2013;

35. Zukhra RM, Muryani M. Hubungan Stres Kerja dengan Kinerja Perawat dalam Melaksanakan Pelayanan Keperawatan di Ruang Instalasi Gawat Darurat (IGD) Rumah Sakit Syafira Pekanbaru. Al-Asalmiya Nurs J Nurs Sci. 2018;7(2):14-21.

36. Muatsiroh A, Siswati S. Hubungan Antara Kecerdasan Interpersonal Dengan Stres Kerja Pada Perawat Instalasi Rawat Inap Di Rumah Sakit Jiwa Daerah Surakarta. Empati. 2017;6(1):34-9.

37. Desima R. Tingkat Stres Kerja Perawat Dengan Perilaku Caring Perawat. J keperawatan. 2015;4(1).

38. Saktiansyah LA, Ahma LAI, Jundillah Z. Analisis Kejadian Stres Kerja Pada Perawat di Kabupaten Konawe Kepulauan Tahun 2017. (Jurnal Ilm Mhs Kesehat Masyarakat). 2017;2(6):1-11.

39. Supardi. Analisa Stress Kerja Pada Kondisi Dan Beban Kerja Perawat Dalam Klasifikasi Pasien Di Ruang Rawat Inap Rumkit TK II Putri Hijau KESDAM I/BB Medan [Tesis]. Univ Sumatera Utara. 2007;

40. Sembiring FY. Hubungan Beban Kerja dan Stress Kerja terhadap Kinerja Perawat di Rumah Sakit Umum Melati Perbaungan Tahun 2012 [Tesis]. Univ Sumatera Utara. 2013;

41. Fardiansyah A. Analisis Hubungan Beban Kerja Dan Lama Masa Kerja Dengan Stres Pada Perawat Di Puskesmas Blooto Kota Mojokerto. Medica Majapahit. 2014;6(2). 
Journal of Healthcare Technology and Medicine Vol. 6 No. 2 Oktober 2020

Universitas Ubudiyah Indonesia

e-ISSN : 2615-109X

42. Pitaloka D. Pengaruh Kondisi Kerja dan Beban Kerja Terhadap Stres Kerja pada Perawat di Ruang Rawat Inap RSU Kaban Jahe Kab. Karo Tahun 2010 [Tesis]. Univ Sumatera Utara. 2010;

43. Nurcahyani E, Widodo D, Rosdiana Y. Hubungan Tingkat Stres Kerja Dengan Kinerja Perawat. Care J Ilm Ilmu Kesehat. 2016;4(1):42-50.

44. Rufli A. Faktor-Faktor Yang Mempengaruhi Stres Kerja Perawat Pelaksana Di Ruang Intensive Rumah Sakit Umum Daerah dr. Zainoel Abidin Banda Aceh Tahun 2014. ETD Unsyiah. 2014;

45. Herlambang S dan AM. Cara Mudah Memahami Manajemen Kesehatan dan Rumah Sakit. Yogyakarta: Gosyen publishing; 2012.

46. RI KK. Undang-undang Republik Indonesia Nomor 44 tahun 2009 Tentang Rumah Sakit. Jakarta; 2009.

47. RI KK. Peraturan Mentri Kesehatan Republik Indonesia Nomor 56 Tahun 2014 tentang klasifikasi dan perizinan Rumah Sakit. Jakarta; 2014.

48. Sabarguna BS, Halimun. Enterprise Resource Planning di Rumah Sakit. Jakarta: Sagung Seto; 2009.

49. Rifiani N, Sulihandari H. Prinsip-Prinsip Dasar Keperawatan. Jakarta: Dunia Cerdas; 2013.

50. Iskandar. Keperawatan Profesional. Jakarta: Rajatrafindo Persada; 2013.

51. Indonesia PPN. Standar Praktik Keperawatan Indonesia. Jakarta: PPNI. 2000.

52. Hanafie A. Peranan Ruangan Perawatan Intensif (ICU) dalam Memberikan Pelayanan di Rumah sakit. 2007;

53. Direktorat Keperawatan dan Keteknisian Medik. Standar Pelayanan Keperawatan di ICU. Jakarta: Departemen Kesehatan Republik Indonesia; 2006.

54. Musliha S. Keperawatan Gawat Darurat. Yogyakarta: Nuha Medika. Yogyakarta: Nuha Medika; 2010.

55. RI KK. Keputusan Mentri Kesehatan Republi Indonesia Nomor 1778/MENKES/SK/XII/2010 Tentang Pedoman Penyelenggaraan Pelayanan ICU di Rumah Sakit. Jakarta; 2010.

56. Waluyo M. Manajemen Psikologi Industri. Jakarta: Indeks Permata Puri Media; 2013.

57. Wijayaningsih K. Psikologi Keperawatan. Jakarta: Trans Info Media (TIM); 2014.

58. Saam Z, Wahyuni S. Psikologi Keperawatan. Depok: Rajatrafindo Persada; 2012.

59. Wijono S. Psikologi Industri dan Organisasi. Dalam Suatu Bidang Gerak Psikologi Sumber Daya Manusia. Jakarta: Kencana; 2010.

60. Munandar A. Psikologi Industri dan Organisasi. Jakarta: UI Press; 2001.

61. Donsu J. Psikologi Keperawatan. Yogyakarta: Pustaka baru press; 2017.

62. WHO (World Health Organization). Gender, Women and Health in Headquarters and Regional Offices. 2004.

63. Indah F. Hubungan shift kerja dengan stres kerja pada perawat di ruang rawat inap Rumah Sakit Umum Daerah Dr. Soegiri Lamongan. 2010;

64. Al Rasasi A, Al Faisal W, El Sawaf E, Hussain H, Wasfy A. Work-related Stres Among Nurses Working in Dubai, a Burden for Healthcare Institutions. American Journal of Psychology and Cognitive Science. Am J Psychol Cogn Sci. 2015;1(2):61-5.

65. Dewi G, Maywati S, Setiyono A. Kajian Faktor Risiko Stres Kerja Pada Perawat IGD dan ICU RSUD Cilacap Tahun 2015. 2015;

66. Sugeng S., Hadi HT, Nataprawira RK. Gambaran Tingkat Stres dan Daya Tahan Terhadap Stres Perawat Instalasi Perawatan Intensif Di Rumah Sakit Immanuel Bandung. Fak Kedokt Univ Maranatha. 2015; 
Journal of Healthcare Technology and Medicine Vol. 6 No. 2 Oktober 2020

Universitas Ubudiyah Indonesia

e-ISSN : 2615-109X

67. Harigopal K. Organizational Stress: A Study of Role Conflict. Sangam books Ltd; 1995.

68. Ismar R, Zarni A, Danardi S. Stres kerja dan berbagai faktor yang berhubungan pada pekerja call center Pt. X di Jakarta. Maj Kedokt Indones. 2011;61(1).

69. Karima A. Faktor-Faktor yang Berhubungan Dengan Stress Kerja pada Pekerja di PT X Tahun 2014. UIN Syarif Hidayatullah. 2014;

70. Nasution HR. Stres Kerja dan Faktor-faktor yang Menyebabkannya. Maj Kesehat Masy Infokes. 2002;6(2).

71. Hidayat AA. Pengantar Konsep Dasar Keperawatan. Jakarta: Salemba Medika; 1994.

72. Pranowo H. Depresi dan Solusinya. Yogyakarta: Tugu Publisher; 2004.

73. Hardjana AM. Stres Tanpa Distres : Seni Mengolah Stres. Yogyakarta: Konisius; 1994.

74. Tarigan L. Faktor-Faktor yang Berhubungan Dengan Stres Kerja Perawat di Ruang Bedah RSU St. Elisabeth Medan. Fak Kesehat Masy Univ sumatera utara. 2004;

75. Anoraga P. Psikologi Kerja. Jakarta: Rineke Cipta; 2001.

76. Notoatmodjo S. Metodologi Penelitian Kesehatan. Jakarta: Rineke Cipta; 2017.

77. Muhammad Iman. S.E S kom. MMMK. Panduan Penyusunan Karya Tulis Ilmiah Bidang Kesehatan Menggunakan Metode Ilmiah. Bandung: Citapustaka Media Perintis; 2015.

78. Pramudya FW. Faktor yang berhubungan dengan stres kerja (studi kasus pada perawat di RSKO tahun 2008). J Penelit tesis. 2009;

79. Nurazizah. Faktor-Faktor yang Berhubungan dengan Stres Kerja Pada Perawat di Ruang Rawat Inap Kelas III RS X Jakarta Tahun 2017. 2017;

80. Anitawidanti H, Nugraheni R. Analisis Hubungan Antara Stres Kerja Dengan Kepuasan Kerja Karyawan Berdasarkan Gender Studi Pada Pt Transindo Surya Sarana Semarang. 2010;

81. Ibrahim H, Amansyah M, Yahya GN. Faktor-Faktor yang Berhubungan Dengan Stres Kerja Pada Pekerja Factory 2 PT. Maruki Internasional Indonesia Makassar Tahun 2016. Al-sihah Public Heal Sci J. 2016;8(1).

82. Ismafiaty. Hubungan Antara Strategi Koping dan Karakteristik Perawat dengan Stres Kerja di Ruang Perawatan Intensif Rumah Sakit Dustira Cimahi. J Kesehat Kartika [Internet]. 2011 [cited 2020 Dec 6];6(2). Available from: https://scholar.google.com/citations?user=FX9hqxMAAAAJ\&hl=id

83. Aiska S. Analisis Faktor-Faktor yang Berpengaruh pada Tingkat Stres Kerja Perawat di Rumah Sakit Jiwa Grhasia Yogyakarta. Yogyakarta Univ Muhammadiyah Yogyakarta Skripsi. 2014;

84. Siagian S. Manajemen Sumber Daya Manusia. Jakarta: Bumi Aksara; 2009.

85. Astuti SDN. Hubungan Beban Kerja dan Kondisi Penyakit dengan Stres Kerja Perawat Pelaksana di Intensive Care Unit (ICU) RSUD Polewali Mandar. 2012;

86. Utomo TWW. Analisis Beban Kerja dalam Rangka Analisis Kebutuhan Pegawai. 2008;

87. Rice PL. Stress and Health. California: Pacific Grove: Broks/Cole; 1999.

88. Anoraga, P \& Suyati S. Psikologi Industri dan Sosial. Jakarta: PT. Dunia Jaya; 1995.

89. Supriatna S, Yuniar Y, Desrianty A. Usulan Strategi Peningkatan Performansi Kerja Perawat Berdasarkan Faktor Pemicu Stres dengan Menggunakan Dimensi Greenberg. REKA Integr. 2014;2(1).

90. Circenis K, Millere I. Stress Related Work Environment Factors: Nurses Survey Results. Int J Collab Res Intern Med Public Heal. 2012; 